\title{
Hazard assessment of debris flows for Leung King Estate of Hong Kong by incorporating GIS with numerical simulations
}

\author{
K. T. Chau and K. H. Lo \\ Department of Civil and Structural Engineering, The Hong Kong Polytechnic University, Hung Hom, Kowloon, Hong Kong, \\ China
}

Received: 8 September 2002 - Revised: 15 December 2003 - Accepted: 5 January 2004 - Published: 9 March 2004

Part of Special Issue "Landslide and flood hazards assessment"

\begin{abstract}
As over seventy percent of the land of Hong Kong is mountainous, rainfall-induced debris flows are not uncommon in Hong Kong. The objective of this study is to incorporate numerical simulations of debris flows with GIS to identify potential debris flow hazard areas. To illustrate this approach, the proposed methodology is applied to Leung King Estate in Tuen Mun. A Digital Elevation Model (DEM) of the terrain and the potential debris-flow sources were generated by using GIS to provide the required terrain and flow source data for the numerical simulations. A theoretical model by Takahashi et al. (1992) improved by incorporating a new erosion initiation criterion was used for simulating the runout distances of debris flows. The well-documented 1990 Tsing Shan debris flow, which occurred not too far from Leung King Estate, was used to calibrate most of the flow parameters needed for computer simulations. Based on the simulation results, a potential hazard zone was identified and presented by using GIS. Our proposed hazard map was thus determined by flow dynamics and a deposition mechanism through computer simulations without using any so- called expert opinions, which are bounded to be subjective and biased.
\end{abstract}

\section{Introduction}

Over seventy percent of the 1098 square kilometers of land in Hong Kong is hilly, and usable flat land is very scarce. Continuous reclamation within Victoria Harbor and elsewhere in Hong Kong cannot completely ease the land shortage problem because of the rapid growth of the population of Hong Kong; the population of Hong Kong increased from 2.2 million in 1953 to 6.8 million in 2003. Inevitably, natural hillsides have been transformed into residential and commercial areas and used for infrastructural development. The risk of debris flow in Hong Kong has been increasing tremendously

Correspondence to: $\mathrm{K}$. T. Chau

(cektchau@polyu.edu.hk) because the rapid development of rural areas next to steep terrain. For example, a series of debris flows occurred on 14 April 2000 in the mountain range west of Leung King Estate. Debris materials of two of these events reached Leung King Estate which was completed only in 1991 and blocked the access road to the Estate. An aerial photograph showing these two debris flows is given in Fig. 1 (Halcrow, 2002).

Recent field trip work in this area, in conjunction with information extracted from aerial photographs, revealed landslides and debris flows have occurred in the past in the mountain range next to Leung King Estate. There is also strong field evidence that this area contains various fault systems. These faults have not been mapped previously by the Hong Kong Geological Survey. More specifically, highly sheared quartz boulders, outcropping mylonite (a foliated fine grained metamorphic rock which shows evidence for strong ductile deformation) and fault breccias (a medium to coarse-grained cataclasite containing more than $30 \%$ visible fragments) are found on the $250 \mathrm{~m}$ high mountain ridge next to Leung King Estate. Pores in the fault breccias indicate the tensile nature of the fault zone, and crystallized quartz deposits are found within these pores. These fault systems typically appear as vertical cliffs in the area, as the weathering process appears to strongly correlate to the existing fault zones. These faults coincide with some of the source areas of the previously reported debris flows (shown in Fig. 1). As it is inferred that future debris flow in this area is likely to recur, there is an urgent need to assess the debris flow hazard of this area.

Regarding landslide hazard assessment mapping, many review articles exist, such as Hansen (1984), Varnes (1984), Einstein (1988, 1997), Fell and Hartford (1997), Hungr (1997), and Leroi (1997). Landslide hazard mapping is very useful in estimating, managing and mitigating landslide hazard for a region. Ideally, a reliable debris flow hazard map should carry appropriate weights from historical landslide events, from geomorphological analysis, and from mechanical or dynamical analysis of slides, falls, and flows of the earth mass. Since all three aspects of hazard analysis involve 


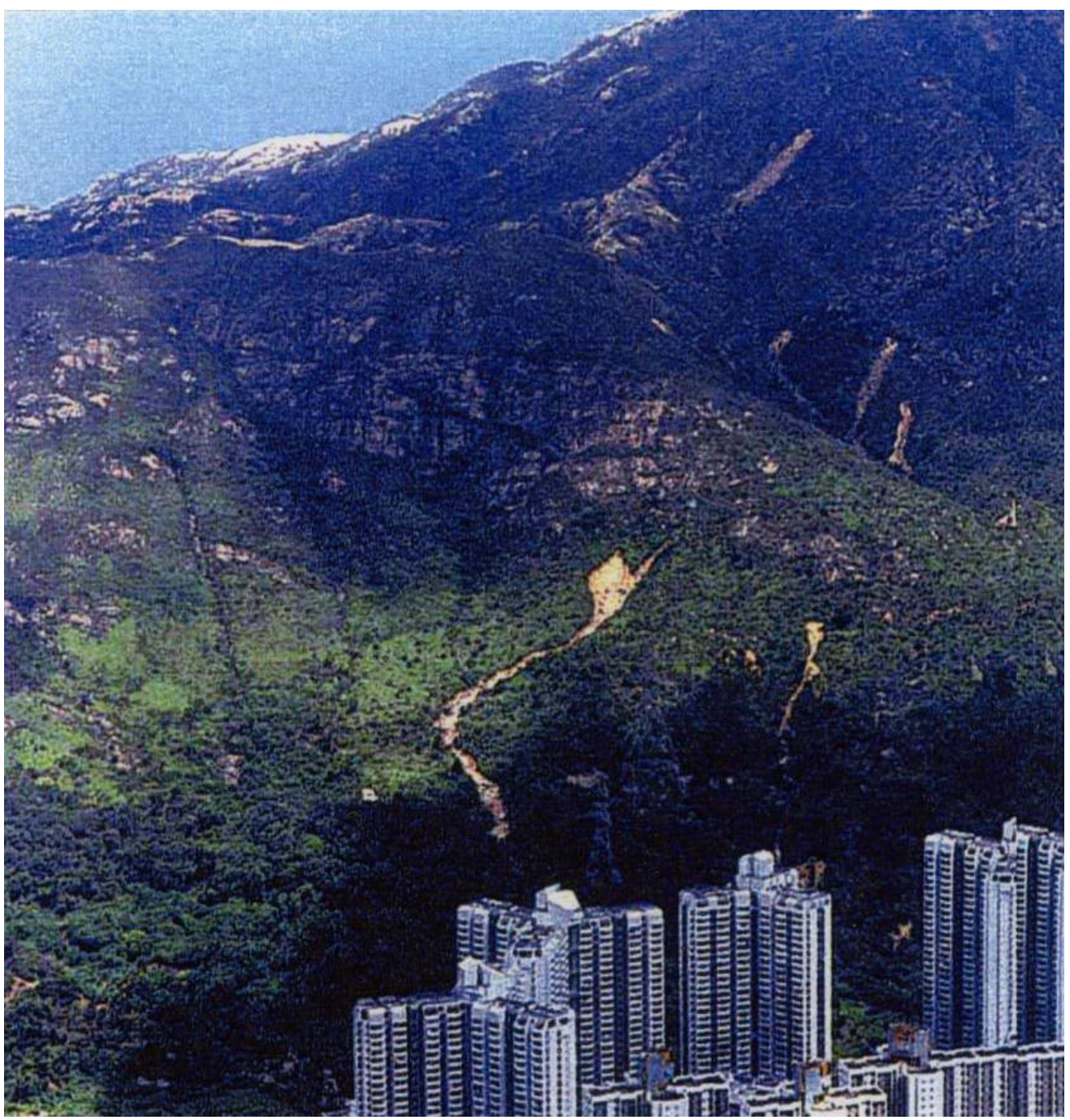

Fig. 1. Debris flows that occurred on 14 April 2000 near Leung King Estate, which is in the foreground.

a large amount of factual, geological and simulated data, the use of computer or information technology is crucial to the success of such analysis. Since the mid 1980s, geographical information systems (GIS) have become a very popular technology for analyzing natural hazards, including landslides (Coppock, 1995). Some of these GIS-based hazard analyses focus on earthquake-induced landslides (e.g. Luzi et al., 2000), and some on rainfall-induced landslides (e.g. Miller and Sias, 1998). GIS analysis has also been proposed to produce rockfall hazard maps (e.g. Cancelli and Crosta, 1994). However, the reliability of the hazard analysis does not depend on which GIS software or platform is used but on what analysis method is employed (Carrara et al., 1999; Guzzetti et al., 2000). Therefore, various methods of analysis have been proposed by many different authors (e.g. Carrara et al., 1991; Dikau et al., 1996; Leroi, 1997; Guzzetti et al., 1999; Carrara et al., 1999; Guzetti et al., 2000; Dai and Lee, 2002a, b; Chau et al., 2003). One main limitation for all these analyses is that dynamics of debris flows or landslides has not been included in the hazard mapping.
The main objective of this study is to propose a methodology for GIS-based hazard mapping that explicitly incorporates the dynamics of debris flow. Leung King Estate is selected for the present study as an example. A terrain model of the Leung King area is first generated by using the Digital Elevation Model (DEM) of the GIS-based digital contour map. Then, the topographical data from the terrain model is used in numerical simulations. The simulations use a flow dynamics model modified from Takahashi et al. (1992). In addition, a new erosion initiation criterion, which depends on the solid concentration in the flow, the percentage of fine solids, and the terminal settling velocity of particles in the flow, proposed by Lo and Chau (2003) is also used. Potential debris sources in Leung King area are identified, within which the potential volume of the largest debris flows along various gullies is estimated. The discharge histogram of the source based upon the flow rate measured by Pierson (1995) for the debris flow induced by the 18 May 1980 eruption of Mountain St. Helens is also assumed. The corresponding solid concentrations in the histogram follow the data adopted 
in the simulation for the Horadani debris flow in Japan (private communication, Takahashi and Nakagawa). Other debris flow parameters are selected based on either suggestions by Takahashi et al. (1992) or interpreted data from the 1990 Tsing Shan event, which occurred not too far from Leung King Estate, as discussed by Lo and Chau (2003) and Lo (2003). The results of the simulations predict the runout of future potential debris flows. A hazard map for Leung King Estate is generated using GIS based upon the results of the numerical simulations. Finally, we also illustrate the generation of another hazard map of Leung King Estate by incorporating the results of numerical simulations and the statistical approach based on past landslide records.

\section{Debris flow model}

In the literature, there is no theoretical flow model that can simulate debris flow over a three- dimensional terrain, that at the same time takes into consideration changing of the bed by erosion and deposition. The only available models that can simulate three-dimensional debris flow approximately are the two-dimensional depth average models (e.g. Savage and Hutter, 1991; Takahashi et al., 1992; O'Brien et al., 1993; Denlinger and Iverson, 2001; Ghilardi et al., 2001). Most of these models did not incorporate erosion and deposition mechanism; only the models by Takahashi et al. (1992) and Ghilardi et al. (2001) incorporated the possibility of erosion and deposition. In this study, we have adopted the model proposed by Takahashi et al. because it has been available for us to use (private communication, Takahashi and Nakagawa). Without going into the details, we should emphasize a major limitation of the model by Takahashi et al. (1992), which is referred as the T-model hereafter. That is, the critical slope gradient for the onset of erosion is assumed constant in the model. This is only an approximation since the critical gradient would naturally depend on the streampower of the flow. Modification to the criterion for the onset of erosion will be discussed in later section.

In the T-model, the mixture is assumed to consist of three components, water, fine solid particles, and coarse solid particles. The content of solids is represented by volumetric concentrations of solid particles in the mixture $\left(c_{s p}\right)$, of coarse solid particles in the mixture $\left(c_{c p}\right)$, of fine solid particles in mixture $\left(c_{f p}\right)$, and of fine solid particles in interstitial fluid $\left(c_{i f}\right)$. They are defined as:

$c_{s p}=\frac{V_{s}}{V_{T}} ; \quad c_{c p}=\frac{V_{c}}{V_{T}} ; \quad c_{f p}=\frac{V_{f}}{V_{T}} ; \quad c_{i f}=\frac{V_{f}}{V_{i}}$,

where $V_{f}, V_{c}, V_{i}$, and $V_{s}$ are the volumes of fine solid particles, coarse solid particles, interstitial fluid, and of total solid particles respectively. Summing all $V_{f}, V_{c}$, and $V_{i}$ equals the total volume of mixture $V_{T}$; and summing $V_{f}$ and $V_{c}$ equals $V_{s}$. Clearly, $c_{i f}$ and $c_{f p}$ are not independent, and it is straightforward to show that they are related by $c_{f p}=\left(1-c_{c p}\right) c_{i f}$.

\subsection{The governing equations}

The flows of the fine and coarse particles through a small control volume satisfy the following continuity equations (Takahashi et al., 1992)

$$
\frac{\partial c_{c p} h}{\partial t}+\frac{\partial c_{c p} M}{\partial x}+\frac{\partial c_{c p} N}{\partial y}=i c_{c p^{*}}
$$

(for coarse solid particles)

$\frac{\partial c_{f p} h}{\partial t}+\frac{\partial c_{f p} M}{\partial x}+\frac{\partial c_{f p} N}{\partial y}=i c_{f p^{*}}$

(for fine solid particles)

where $M$ and $N$ are the average fluxes over flow depth $h$ along the $x$ - and $y$-directions respectively. The velocity of either gain or loss of the solid particles is denoted by $i$ which is less than zero for deposition, and greater than zero for erosion. The subscript "**" indicates either the solid concentration of the eroded or the deposited debris mixtures at the static bed. In this model, discharge histograms of both $c_{c p}$ and $c_{f p}$ must be input at an upstream boundary.

The momentum equations of the debris mixtures flowing along the $x$ - and $y$-directions are respectively (Takahashi et al., 1992):

$$
\begin{aligned}
& \frac{\partial M}{\partial t}+\beta \frac{\partial u_{0} M}{\partial x}+\beta \frac{\partial v_{0} M}{\partial y}= \\
& g h \sin \theta_{b x}-g h \cos \theta_{b x} \frac{\partial\left(z_{b}+h\right)}{\partial x}-\frac{\tau_{b x}}{\rho_{T}}, \\
& \frac{\partial N}{\partial t}+\beta \frac{\partial u_{0} N}{\partial x}+\beta \frac{\partial v_{0} N}{\partial y}= \\
& g h \sin \theta_{b y}-g h \cos \theta_{b y} \frac{\partial\left(z_{b}+h\right)}{\partial y}-\frac{\tau_{b y}}{\rho_{T}},
\end{aligned}
$$

where $g$ is the gravitational constant $\left(9.81 \mathrm{~m} / \mathrm{s}^{2}\right) ; z_{b}$ is the deposit thickness; $u_{0}$ and $v_{0}$ are the velocities along $x$ - and $y$ directions respectively; $\beta$ is a momentum correction factor; $\rho_{T}$ is the equivalent density of the debris mixture; $\theta_{b x}$ and $\theta_{b y}$ are the tangents at the bed along the $x$ - and $y$-directions respectively; and $\tau_{b x}$ and $\tau_{b y}$ are the base shear resistances along the $x$ - and $y$-directions respectively. Full details of the T-model are referred to Takahashi et al. (1992) and Takahashi (1981, 1991).

\subsection{Modifications made to Takahashi's model}

A new erosion initiation criterion has been proposed by Lo and Chau (2003). The full details of this modification are beyond the scope of the present study. Only the main results will be summarized here. In particular, the minimum energy gradient, than $\theta_{\min }$ (i.e. a natural slope with energy gradient $\theta$ 


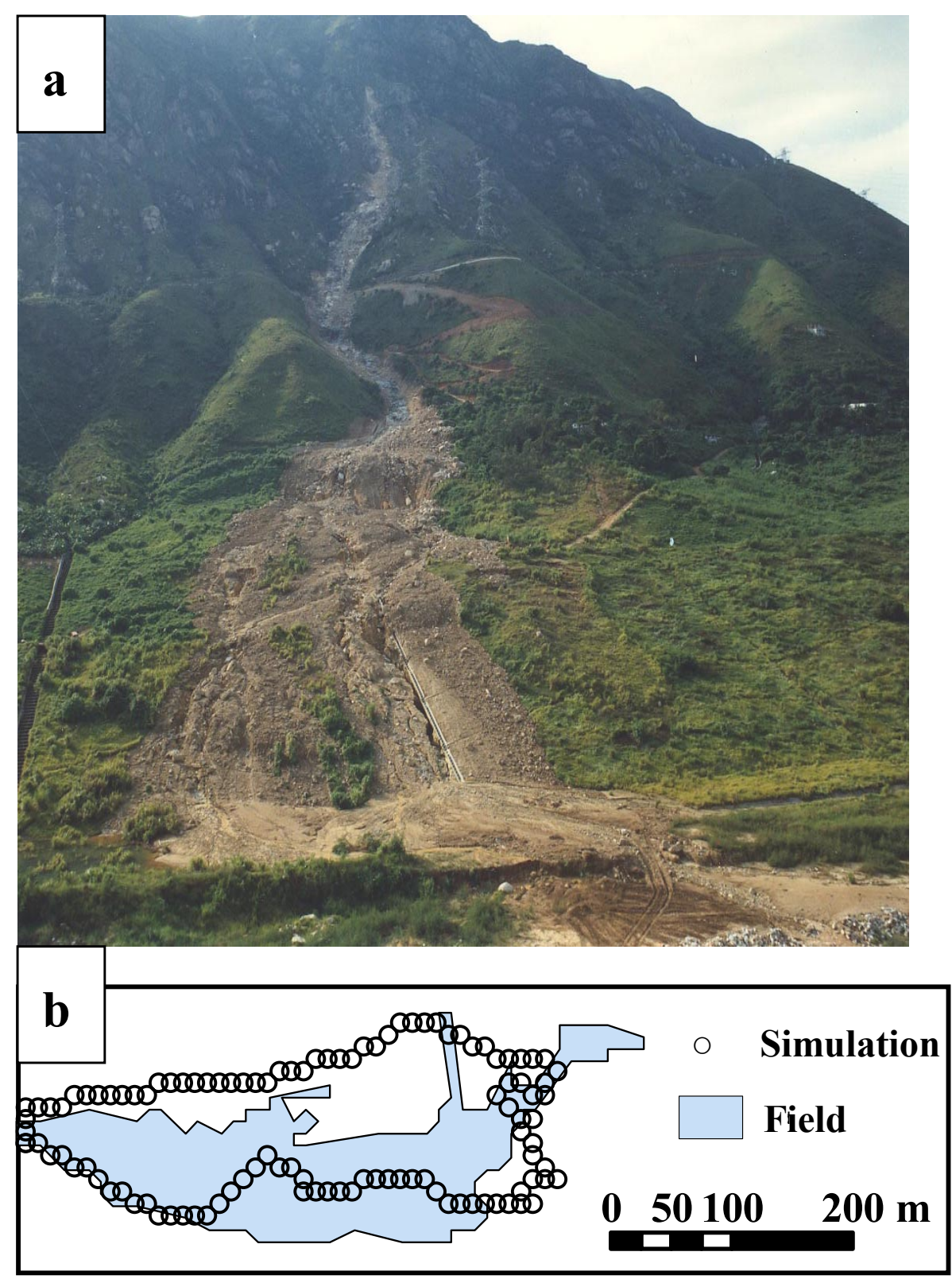

Fig. 2. (a) A photograph of the 1990 Tsing Shan debris flow; (b) Numerical simulation and field record. The shaded area labeled as "field" in (b) is the field observation of the deposit area, whereas the open circles "o" denote the boundary of the deposit predicted in the numerical simulation.

less than $\theta_{\min }$ will suffer no erosion) is derived as (Lo, 2003; Lo and Chau , 2003):

$$
\tan \left\{\sin ^{-1}\left[\frac{c_{s p} G_{s} \rho_{w}\left(\int_{P_{f}}^{1} \omega_{r} d P\right) /\left(1-P_{f}\right)}{F \rho_{m} \sqrt{u_{0}^{2}+v_{0}^{2}}}\left(\frac{\sigma-2 \rho_{m}}{\sigma-\rho_{m}}\right)\right]\right\}(6)
$$

where $c_{s p}, F, G_{s}, \sigma, \rho_{w}, P_{f}, P, u_{0}, v_{0}, \rho_{m}$ and $\omega_{r}$ are solid concentration in the flow, excess fraction of the streampower available for erosion (typically $0.1-0.2$ ), specific gravity of the solid particles, density of the solid particles, density of water, percentage of fine solid (i.e. particle size less than $63 \mu \mathrm{m}$ ), percentage of solid mass in the fluid with a certain particle size $d$, average flow velocity along the $x$ direction, average flow velocity along $y$-direction, density of the muddy water (i.e. the interstitial fluid), and relative settling velocity of particle of size $d$ respectively. The main contribution from (6) is that the start of erosion is no longer set as an empirical constant, but a function of the fluid properties and flow energy. Thus, in general, $\theta_{\min }$ becomes a function of the flow and thus changes with the position of the slope (as the flow parameters change along the slope profile). As shown by Lo (2003) and Lo and Chau (2003), after incorporating this erosion criterion, the simulations of the T-model fit better with the field record of the 1990 Tsing Shan debris flow. The results are reported in the next section. 


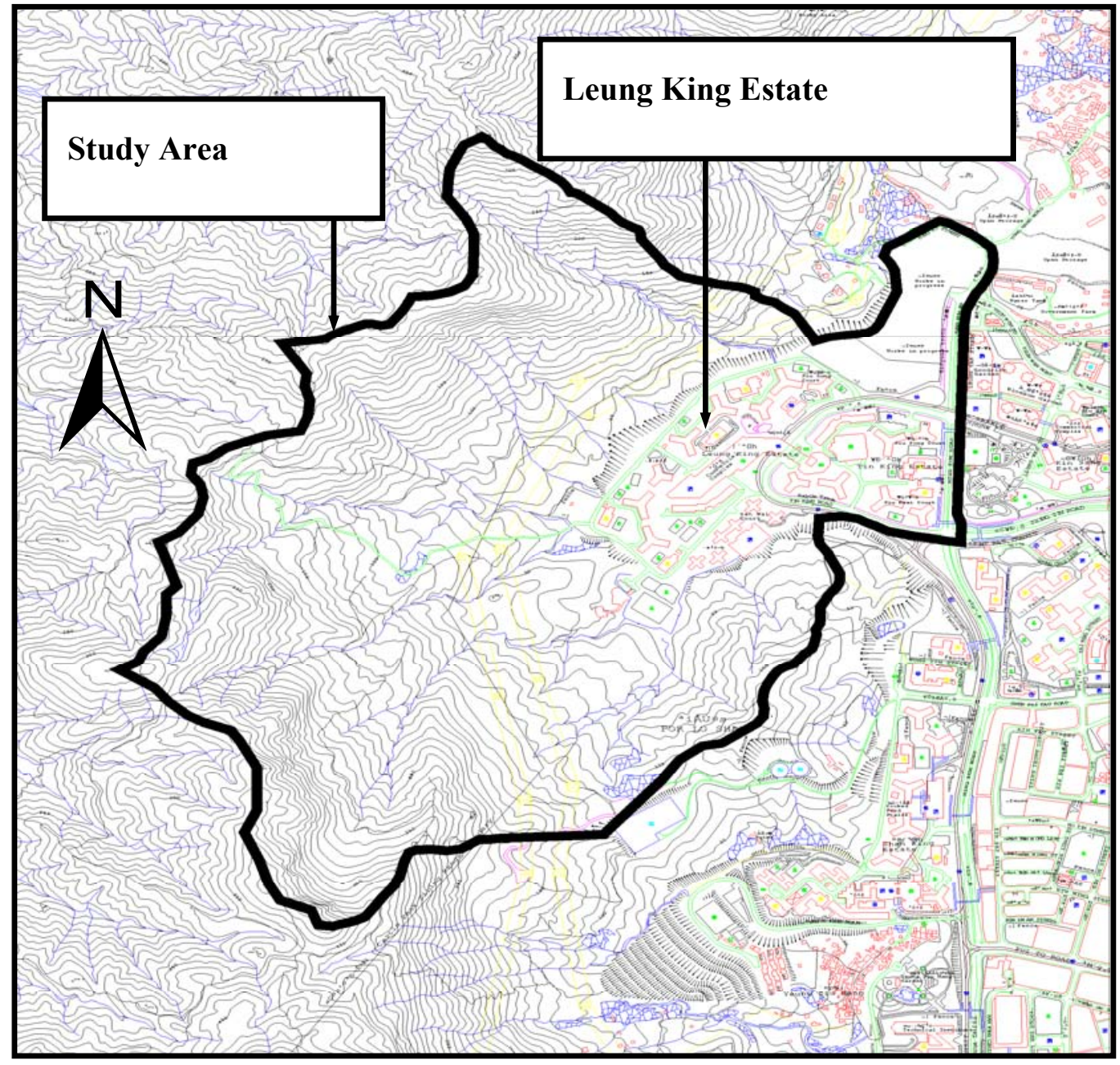

Fig. 3. The study area for debris flow hazard assessment of Leung King Estate.
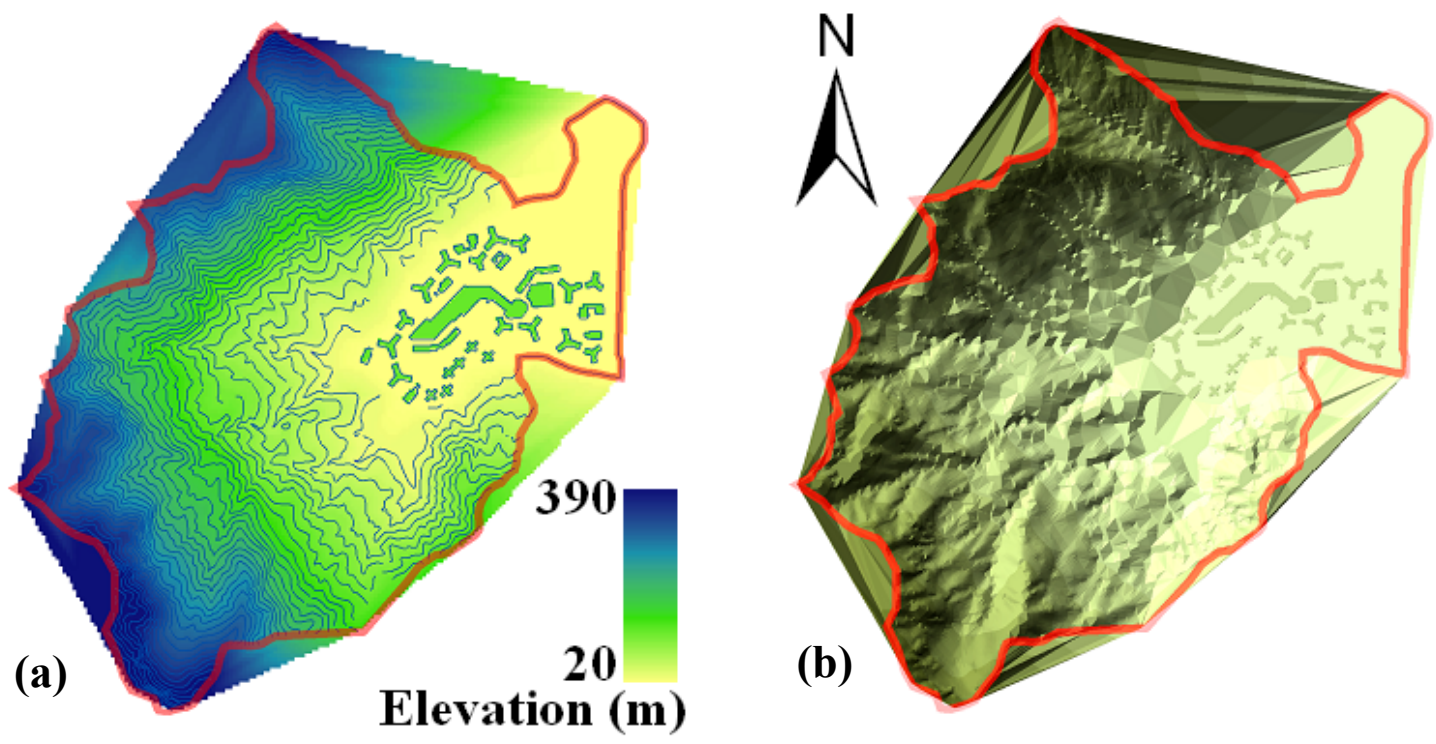

Fig. 4. (a) A contour map for generating the DEM of Leung King Estate; (b) the Digital Elevation Model (DEM) of Leung King Estate. 
If the channel slope $\theta$ along a gully is larger than the minimun energy gradient $\theta_{\text {min }}$ given by Eq. (6), the velocity of erosion $i$ defined in Eq. (2) can be determined from the following empirical formula (Takahashi et al., 1992):

$i=K \sqrt{g h} \sin ^{3 / 2} \theta$

$$
\left[1-\frac{\sigma-\rho_{i}}{\rho_{i}} c_{c p}\left(\frac{\tan \alpha}{\tan \theta}-1\right)\right]^{1 / 2}\left(\frac{\tan \alpha}{\tan \theta}-1\right)\left(c_{c \alpha}-c_{c p}\right) \frac{h}{d}
$$

where $K, g, \sigma, \rho_{i}, h, d, \alpha$ and $c_{c \alpha}$ are a numerical constant (typically 0.06), the gravitational constant, the density of the interstitial fluid, the density of the debris material, the flow depth, the mean diameter of solid particles, the dynamic frictional angle, and the equilibrium solid concentration. Equation (7) is obtained by assuming that erosion is caused by the dynamic action of the shear stress on the bed by the interstitial fluid of the overlying sediment-laden flow. This erosion process is assumed to continue as long as the entrained-solids is less than the equilibrium value $c_{c \alpha}$. As shown in Eq. (7) that when $c_{c p}$ increases to $c_{c \alpha}$, the erosion velocity $i$ diminishes to zero.

\subsection{Parameter calibration using the 1990 Tsing Shan debris flow}

To illustrate the applicability of the present numerical model (the modified Takahashi model or the MT model), the 1990 Tsing Shan debris flow occurred on the eastern flank of Tsing Shan is selected for parameter calibration. This event occurred on 11 September 1990 and is the largest debris flow in the recorded history of Hong Kong (see Fig. 2a). It was estimated that a total of $19000 \mathrm{~m}^{3}$ of debris were deposited down slope. The total travel distance is about $1 \mathrm{~km}$ (King, 1996). Although this event is relatively well-documented, similar to most other debris flows reported elsewhere no discharge histrograph was measured. Approximation becomes inevitable in generating the histrographs for numerical simulations. One simple way to establish the discharge histrograph is to assume that the general characteristics of discharge are similar for different events. In particular, a detailed literature review shows that most discharge histrographs measured in field have an initial sharp increase in discharge, followed by an exponential decay of the flow rate. One such example is the debris flow measured after the 1980 eruption of Mount. St. Helens (Pierson, 1995). Therefore, in this study, the discharge histrograph recorded at Mount. St. Helens will be scaled down to match to the total volume of debris reported for the 1990 Tsing Shan debris flow. Regarding the solid (both fine and coarse) concentrations in the discharge, we use the solid concentrations adopted for the Horadani debris flow simulation (private communication, Takahashi and Nakagawa). Most of the other model parameters can be estimated from the report of King (1996); if not, they have been adopted from the data set for the Horadani debris flow simulation. For example, the coarse and fine solid concentrations were obtained from the laboratory results reported by King (1996).
Figure $2 \mathrm{~b}$ shows the results of a particular simulation of the 1990 Tsing Shan debris flow by using the MT-model summarized in the previous section. For the purpose of comparison, the actual field observation is also reported Fig. 2 a. Figure 2 shows that the simulation result is comparable to that of the field observation, both in terms of the total deposit area as well as the runout displacement. The shaded area labeled as "field" in Fig. 2b is the field observation of the deposit area, whereas the open circles denote the boundary of the deposit predicted in the numerical simulation. Based upon this comparison, the model parameters are calibrated and are adopted for the simulations for Leung King Estate area. In addition, we have also conducted a very comprehensive parametric study of the choice of various input parameters (Lo, 2003), but the details will not be given here.

We should emphasize here that the main objective of the present study is not on the discussion of a particular debris flow simulation model (such as the MT-model), but instead on the introduction of a methodology that incorporates numerical simulation for hazard mapping. Therefore, the details of the numerical simulation are not crucial here. The full details are referred to Lo (2003). Indeed, the same methodology can also be applied for hazard mapping with other suitable numerical simulation models, if it is deemed appropriate.

\section{Incorporation of numerical simulations with GIS mapping}

In this section, we will demonstrate how to produce a "flowdynamics-based" hazard map for Leung King Estate incorporating GIS technology. The selected area for our hazard study is shown in Fig. 3, and Leung King Estate is also indicated in the figure. The boundary of the study area coincides with the catchment area for Leung King Estate.

\subsection{Generation of DEM for simulation}

In order to generate the topographical data required for the simulation using MT-model, a GIS-based digital map given in Fig. 4a is first converted to a Digital Elevation Model (DEM) (shown in Fig. 4b). The resolution of the DEM is $10 \mathrm{~m} \times 10 \mathrm{~m}$ and is saved as raster in ArcGIS. This pixel or raster-based DEM for Leung King Estate is then converted to a data file format readable by the MT-model for the computer simulation. Each data point contains elevation and coordinates, and this data set forms our topographical model.

\subsection{Source identification and flow quantification}

\subsubsection{Source zones}

Next step is to identify the potential source zones. After field trip work in the area and after studying the available aerial photographs, eight potential source zones were identified. They are labeled as (a) to (h) in Fig. 5. From field observation, the average thickness of colluvium in the source 


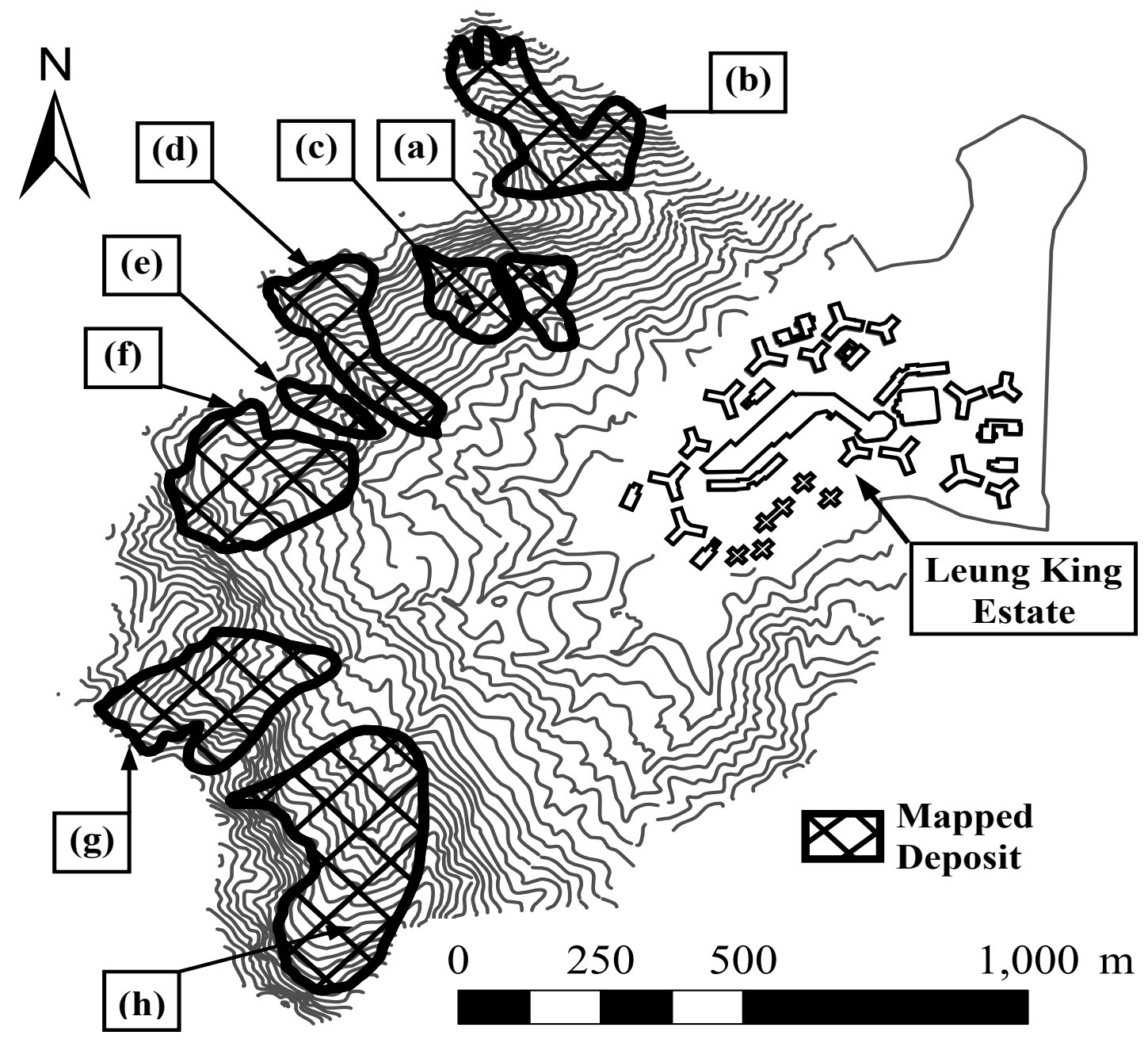

Fig. 5. Eight potential debris source zones, denoting by (a) to (h).

areas is estimated from $1.3 \mathrm{~m}$ to $1.7 \mathrm{~m}$. The total volume of soil and boulders that may be mobilized from each zone can then be estimated from using a standard functions available in ArcGIS. The accuracy of these estimated volumes can always be improved if more thorough site investigations are conducted. These volumes form the basis for constructing our inflow histrographs at the upstream boundary of each simulation.

\subsubsection{Discharge histrograph}

In particular, after scaling the discharge histrograph of the debris flow of Mount. St. Helens, the histrograph for each source zone can be generated. They are given in Fig. 6 for all source zones (a) to (h). In order to put the magnitude of the discharge in the right perspective, all histrographs shown in Fig. 6 are given on the same scale. As expected from Fig. 5, the largest potential debris flow is likely to be from source area (h) followed by source area (f). The smallest discharge is from source area (e).

\subsubsection{Solid concentration histrograph}

The ratio of coarse to fine solid concentrations are determined from laboratory data of soil sample from Tsing Shan, whereas the histrographs of solid concentrations are adopted from those used for the Horadani debris flow simulation. The solid concentration histrographs are given in Fig. 7 for all source areas (a) to (h). Again all plots are given in the same scale for easy comparisons. The amount of solid involved in each of these numerical simulations can be integrated from the discharge histrographs given in Fig. 6 in connection with the solid concentrations given in Fig. 7.

\subsection{Results of numerical simulations}

The results of the numerical simulations are given in Fig. 8 using ArcGIS. The deposition fan is marked by the dotted lines, and the thickness of the deposition is indicated by the darkness of the shaded areas within the marked areas of deposition. At some locations, the spatially distributed debris deposition can be up to $6 \mathrm{~m}$ thick (approximately 


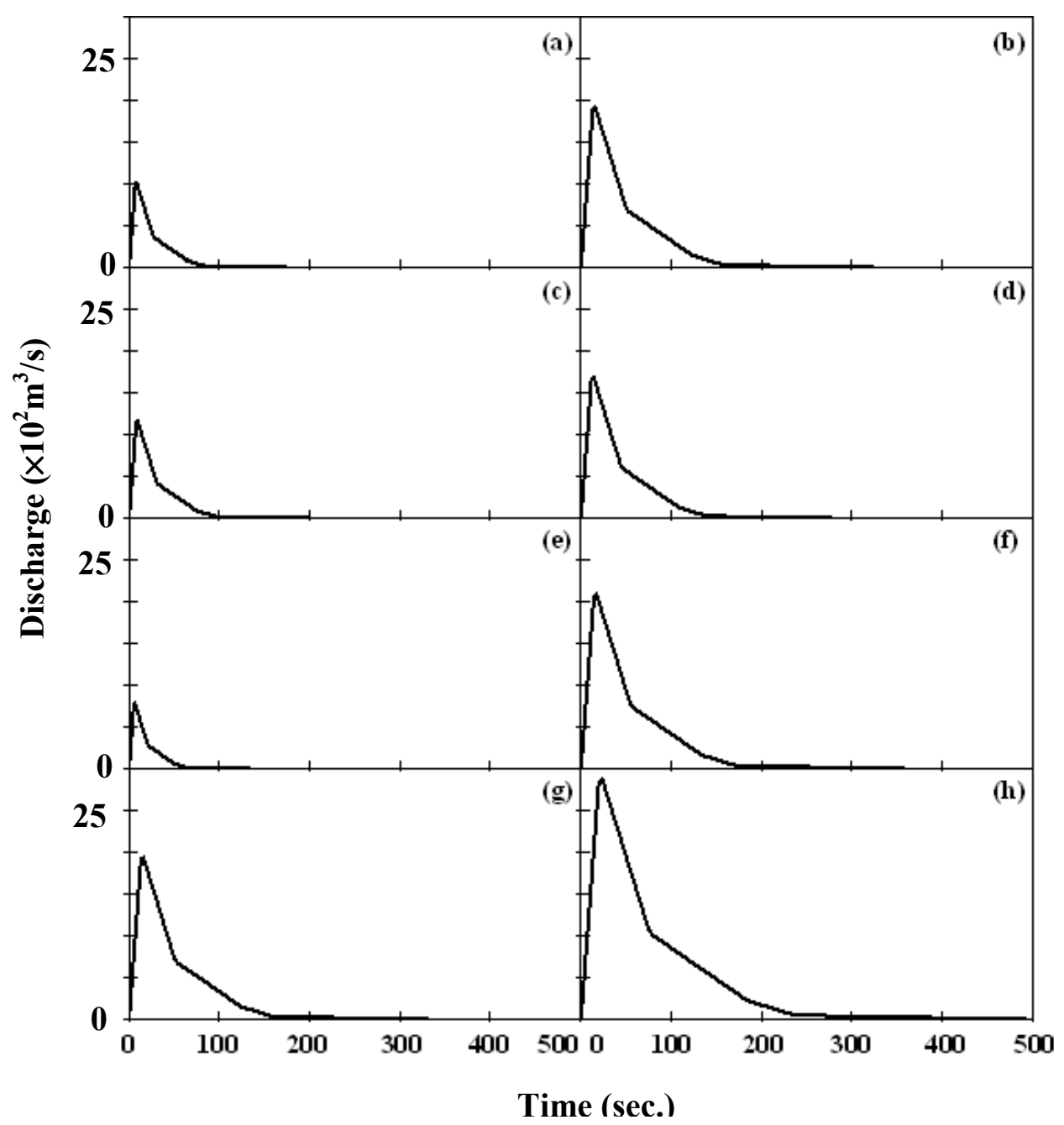

Fig. 6. Discharge histrographs for the source zones (a) to (h) shown in Fig. 5. The shapes of these histrographs are similar to that of the debris flow occurred after the 1980 eruption of Mount St. Helens.

corresponding to the height of 2 storeys). Except for simulation from source area (e), all simulated debris flows reach the buildings located inside Leung King Estate. The "Y"-shaped and "+"-shaped buildings are residential blocks within the Estate while other facilities (like the shopping mall, primary and secondary schools) are denoted by polygons of different shapes. Although the largest volume of debris is likely to be from source zone (h), the most dangerous debris flow is the one from source zone (b) due to the proximity of the source zone to downslope buildings and due to the steepness of the gully in which this debris flow would travel. The results of these simulations should, however, be interpreted with caution since they probably represent the worst scenarios related to these source zones. In the case of heavy rain, one or more of these source zones may become fluidized and debris flow initiation may happen. However, it is very unlikely that all potential debris flows will be mobilized at the same time, and the actual involved volume may also vary depending on the intensity of rain.

\subsection{Debris flow hazard map}

\subsubsection{Hazard map based solely on numerical simulation}

By assuming the worst-case scenario that all debris flows occur at the same time, we extract the maximum depth at each location from all eight numerical simulations shown in Fig. 8 and the result is given in Fig. 9. The flow-dynamics-based plot provides a hazard map to identify the most dangerous areas within the Estate. Based upon this map, remedial and mitigation measures can be planned. The advantage of this kind of hazard map is that it is based purely on dynamics, instead of on expert opinions or on past debris flow records. It is believed that it provides an improvement on the traditional way of generating GIS-based hazard maps, which are based purely on statistical approach. It is because debris flow hazard level at a particular location should depend on whether there is a chance of being affected by nearby potential sources instead of based purely on past records and statistics. 


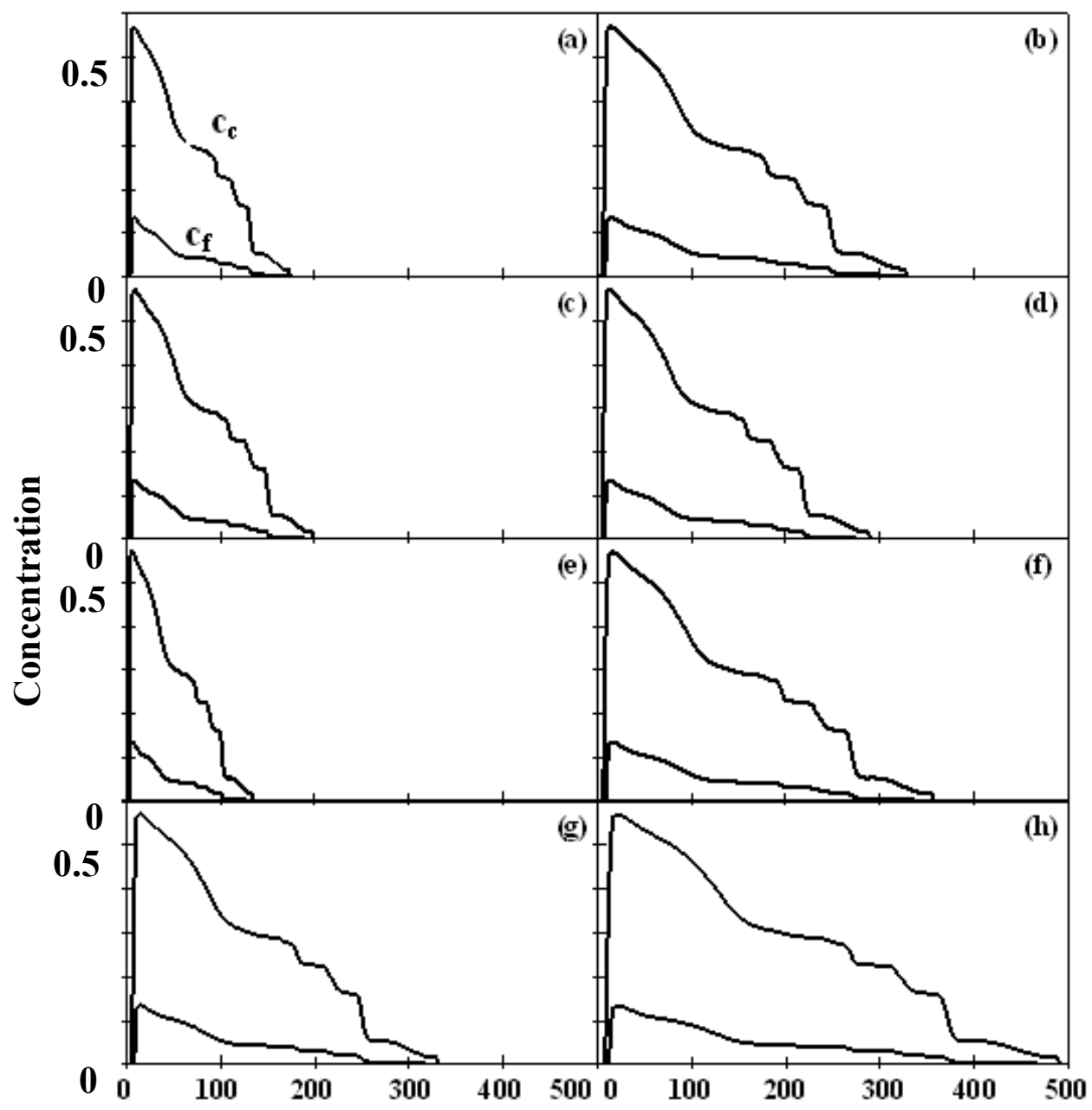

Time (sec.)

Fig. 7. Solid concentration histrographs for coarse, $c_{c p}$, and fine, $c_{f p}$, particles for the source zones (a) to (h) shown in Fig. 5 . The ratio of the fine to coarse solid concentration is set according to field measurements for Tsing Shan, whereas the shapes of histrographs are set according to the Horadani debris flow of Japan.

Of course, one can always argue that the estimation of the total volume of mobilizable colluvium may not be accurate, and that the flow model itself (MT-model in this case) may involve unwanted simplifications and assumptions. However, we can always conduct a more detailed site investigation such that the extent and thickness of colluvium can be estimated with higher certainty (if time and budget allow). Once a better or an improved theoretical model is available, the simulation can be conducted with higher accuracy. The main focus here is not on the absolutely accuracy of the hazard estimation, but on the idea of combining the sound theoretical approach in GIS-base hazard mapping, such that expert opinion can be reduced to a minimum.

In addition, the results of our numerical simulations can also be normalized to give a hazard index map. For example, Fig. 10 gives a plot of the hazard index defined as the normalized thickness of the deposition (with respect to the maximum predicted thickness of the deposit in the area). In this figure, we also have labeled the most affected locations; they are a primary school (as P), a secondary school (as S), and two building blocks (as B1 and B2). It seems that debris flow barriers should be installed in the future in protecting building blocks, S, B1, B2 and P. Although this plot is essentially the same as Fig. 9, it provides a normalized basis for combining the results of numerical simulations with other factors affecting the hazard estimation.

\subsubsection{Hazard map combining numerical simulations with other factors}

If numerical simulations presented in the paper are not available, the traditional way of assessing landslide hazard is to correlate statistically the local geological features, including elevation, slope angle, and geology and environmental effects to the actual landslide data. For example, in Fig. 11 the top four hazard index maps are given to indicate the effects 


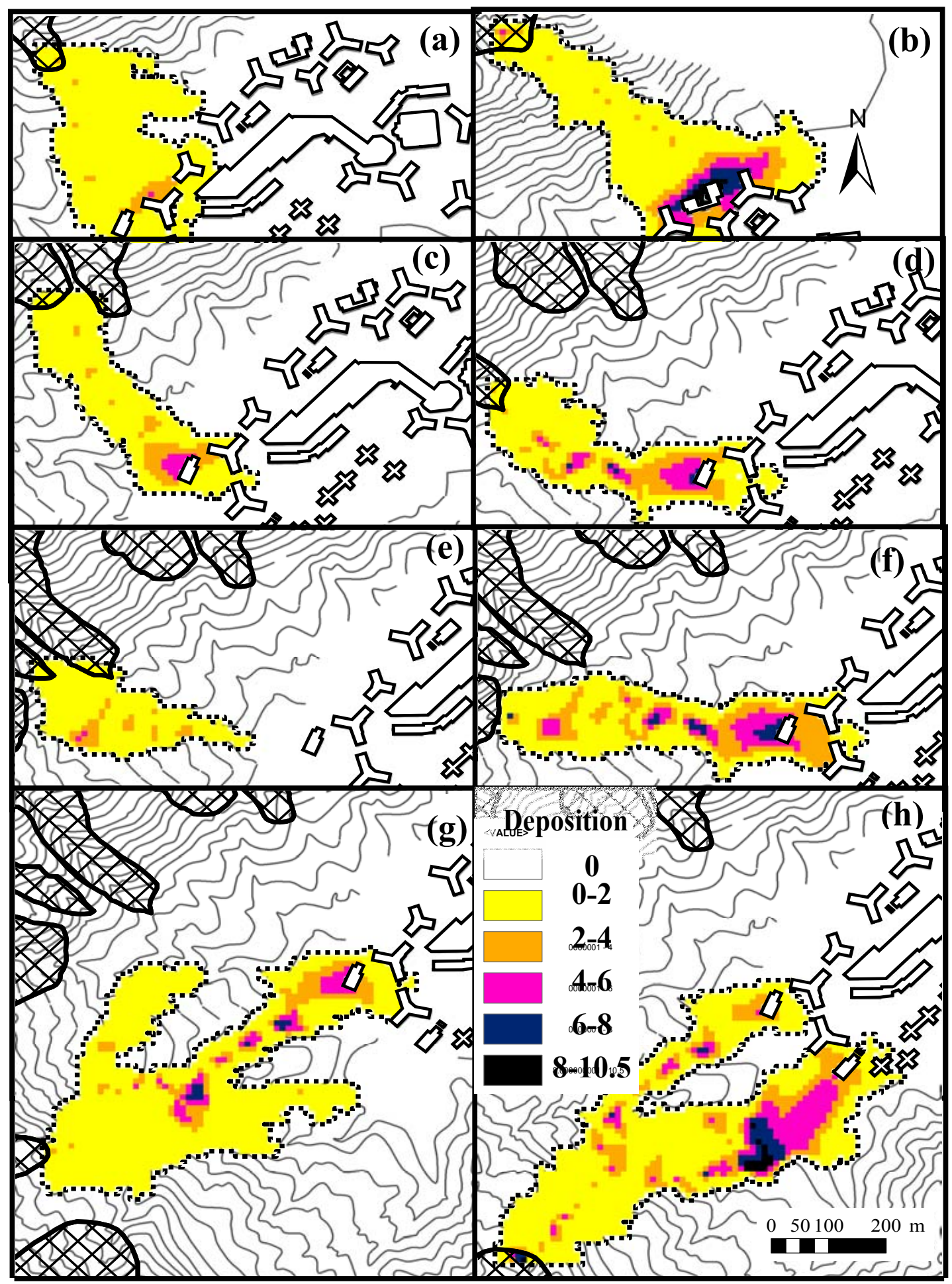

Fig. 8. Results of the debris flow simulations for the source zones (a) to (h) shown in Fig. 5. Building footprints are given as unfilled polygons. The legends in (h) for deposition thickness in metres.

of other factors, such as elevation, slope angle, geology and rainfall. All these maps have been normalized with respect to the maximum value of the probability of debris flow occurrence within any class of each factor.
For these four hazard index maps, we refer to the analysis by Evans et al. (1999), who have examined the correlations between natural terrain landslide (or debris flow) occurrence and degree of erosion, terrain landform, lithology, 


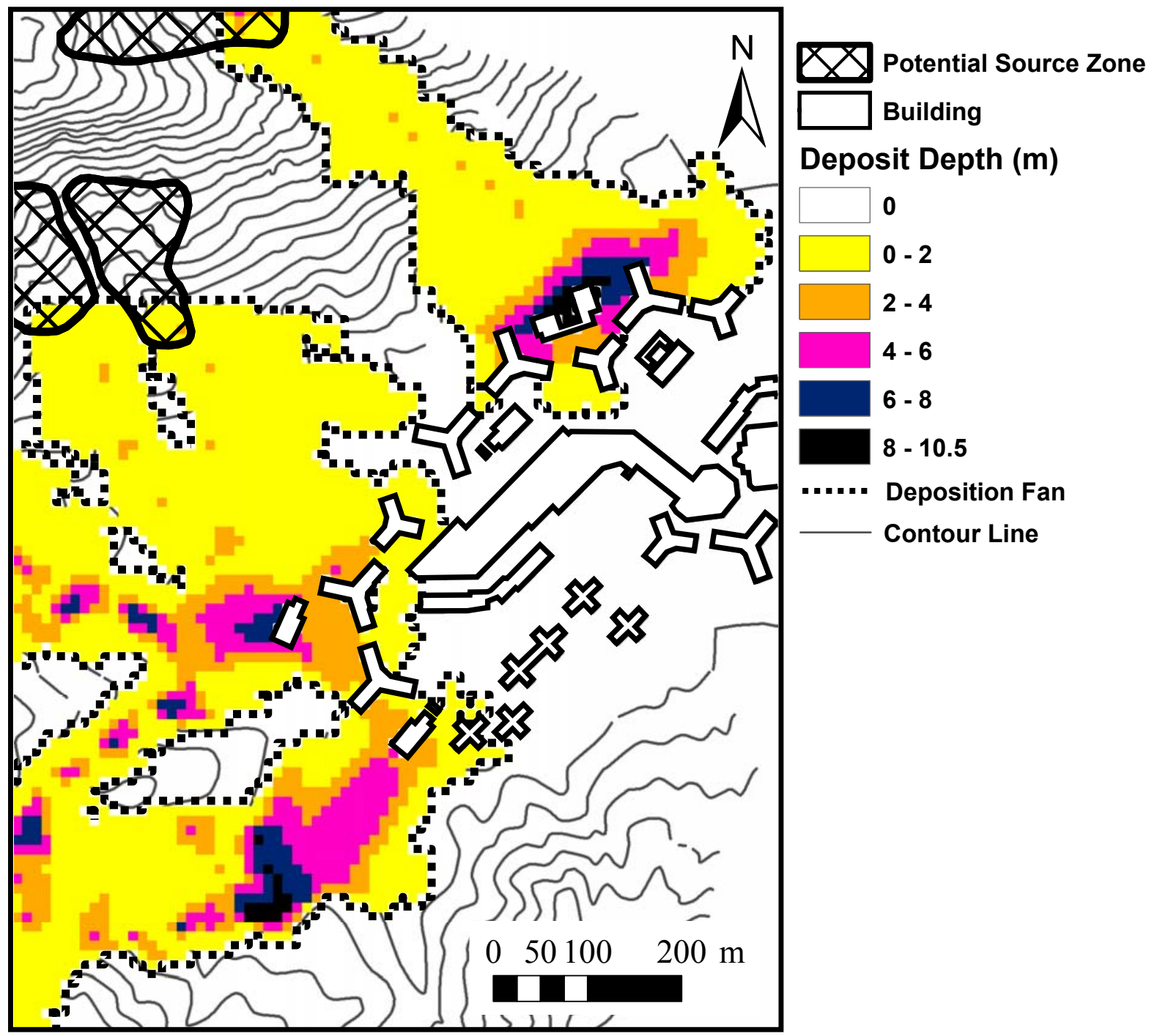

Fig. 9. Combined result of the debris flow simulations of the source zones (a) to (h) shown in Fig. 8. Building footprints are given as unfilled polygons. The legends in (h) for deposition thickness are in meters.

slope angle, slope aspect, elevation and vegetation for Hong Kong using aerial photographs and GIS. For example, the geological factor "elevation" can be divided into 4 classes as: 0-200 m, 200-400 m, 400-600 m and > 600 m (Evans et al., 1999). Table 12 of Evans et al. (1999) shows that the densities of debris flow events per survey area (event $/ \mathrm{km}$ ) for these 4 classes are 39.41, 40.06, 36.51, and 19.32 respectively. Note that Evans et al. (1999) termed debris flow as natural terrain landslides in their report. Consequently, normalization gives the hazard index for the elevation hazard map with index values of $0.9838,1,0.9114$ and 0.4823 for the 4 different classses. Thus, an elevation-based hazard index map is generated with indices less than or equal to 1 . Similarly, the data given in Tables 8 and 10 of Evans et al. (1999) can lead to the hazard index maps for geology and slope angle shown in Fig. 11. The rainfall hazard index maps are obtained from rainfall maps published by the Hong Kong Observatory from 1990 to 2000 . In particular, the monthly rainfall maps with the maximum values within the 11 year period from 1990 to 2000 are extracted and averaged using raster calculator available in ArcGIS to yield the rainfall hazard raster map. Then, the map is normalized with respect to the maximum average rainfall value to yield the hazard index map shown in Fig. 11. The full details of the establishment of these hazard maps can be referred to Chau et al. (2003).

Once the hazard index maps with the maximum index value being unity are obtained for each factor (either geology or environment), they can be combined to yield a final hazard map by assigning different weighting to each factor. For example, if hazard indices $\left(H_{j i}, i=1,2, \ldots, n\right.$, where $n$ is the number of classes in each factor; $j=1,2 \ldots, m$, where $m$ being the number of factors) with weightings 


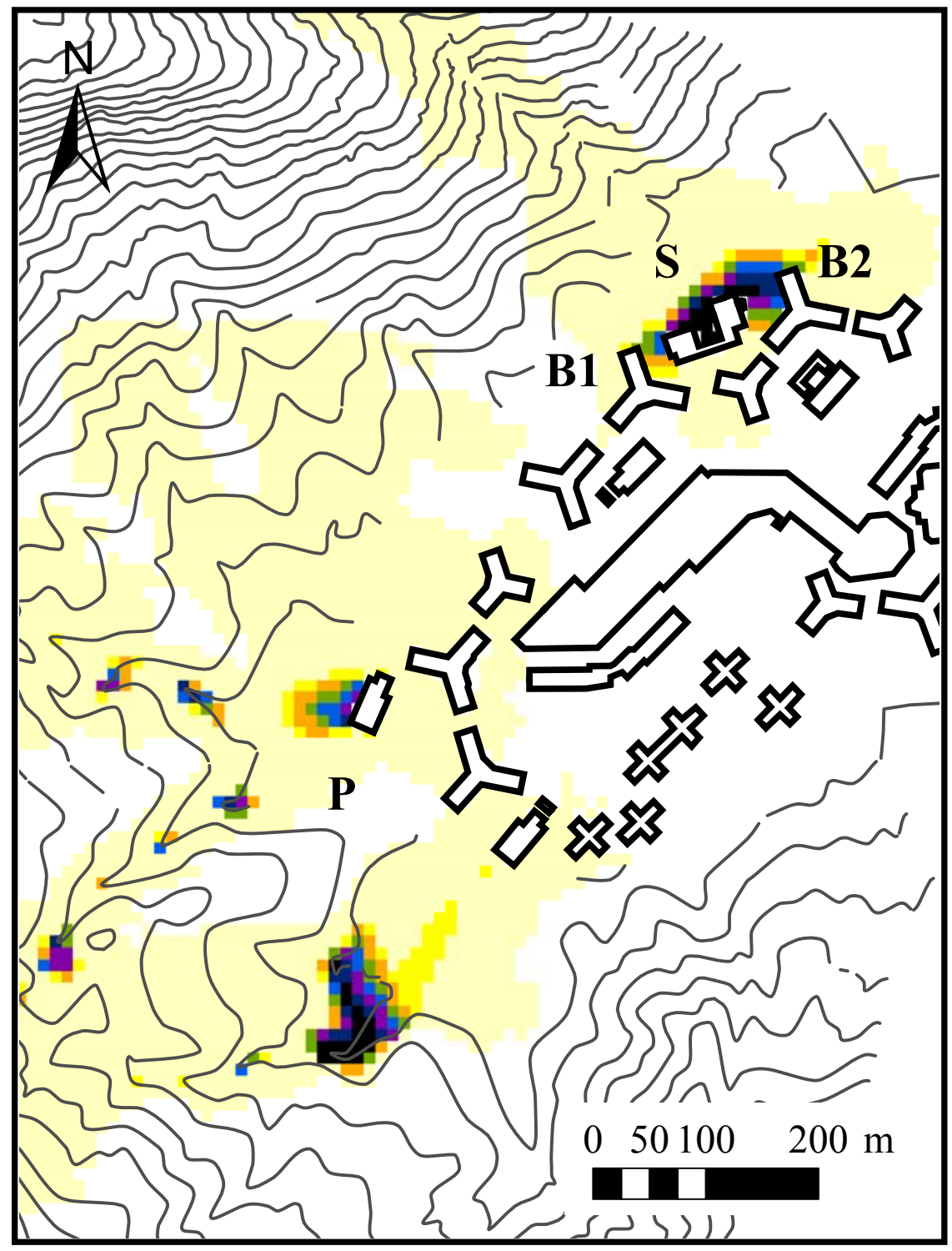

Hazard Index

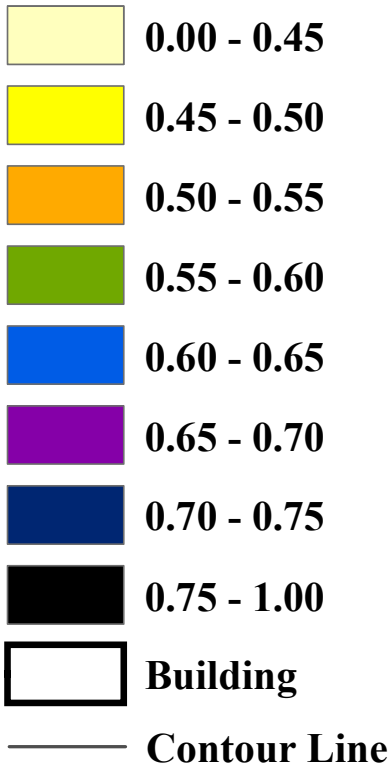

Fig. 10. A hazard map based solely on computer simulations. The maximum index on the map is one. Building footprints are given as unfilled polygons.

$\left(W_{j}, j=1,2, \ldots, m\right)$ are given, a hazard map can be generated. The number factors used in generating the hazard maps shown in Figs. 11a and $\mathrm{b}$ are $m=4$ and $m=5$ respectively. The landslide hazard at each location $\boldsymbol{x}$ (denoted by pixel of $10 \mathrm{~m} \times 10 \mathrm{~m}$ ) is calculated according to:

$\operatorname{Hazard}(\boldsymbol{x})=\sum_{j=1}^{m}\left[W_{j} H_{j i}(\boldsymbol{x})\right] / \sum_{j=1}^{m} W_{j}$.

Since the values on the right hand side of (8) are scaled with respect to the sum of the weightings, the maximum value of $\operatorname{Hazard}(\boldsymbol{x})$ at any pixel must be less than or equal to 1 . The calculation of hazard map based upon Eq. (8) can be done efficiently by using "raster calculator" available in ArcGIS. Figure 11a shows a hazard map based purely on statistical analysis without using simulation results given in Fig. 10, by combining the top 4 hazard index maps for elevation, slope angle, geology and rainfall with corresponding weightings of $1.0,1.0,0.5$ and 1.0.

However, if one incorporates the hazard index of numerical simulation given in Fig. 10 with a weighting of 1.0 (which is selected for illustrative purpose only and in fact any weighting can be assigned) but assumes the total weighting in the denominator of (8) constant, Fig. $11 \mathrm{~b}$ is obtained. Comparison of Figs. 11a and $\mathrm{b}$ reveals that the statistical hazard map severely underestimates the potential debris flow hazard at all building blocks S, P, B1 and B2 shown in Fig. 10. Thus, the traditional approach based purely on past landslide record does not necessarily yield reliable results compared to the flow-dynamics-based estimation. Therefore, it is unsafe to estimate hazard level based simply on a 

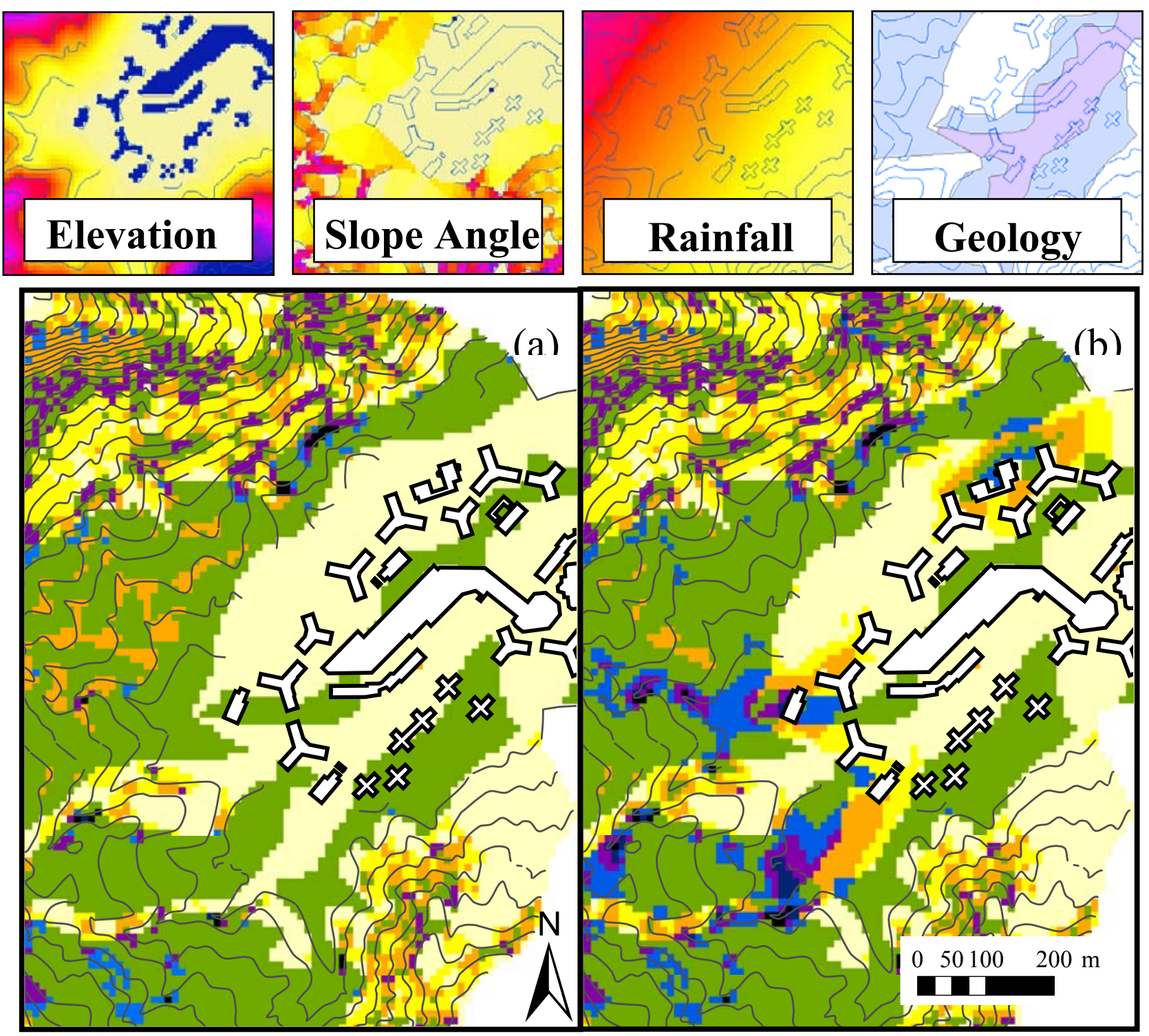

Fig. 11. Four basic factor hazard maps for elevation, slope angle, rainfall and geology are shown in the top row. (a) A hazard map combining the top four hazard maps (but without the results of numerical simulations); (b) A hazard map incorporating the results of numerical simulations given in Fig. 10 (the weightings for each factor are given in the text).

statistical approach, and numerical simulation results (which estimating the travel distance of event from each potential debris flow source zone) must be incorporated.

\section{Conclusions}

We have presented an approach to estimate the potential hazard of debris flow by incorporating the results of numerical theoretical simulations of debris flow and GIS technology. The flow model adopted here is that of Takahashi et al. (1992), with appropriate modifications incorporated. The Tsing Shan debris flow of 1990 is used as a bench mark to calibrate the required parameters and data for simulations, and Leung King Estate is selected as an example to illustrate how the debris flow hazard in term of deposition coverage and thickness can be generated. It is expected that the present methodology will be further applied to other areas in Hong Kong and other parts of the world. It is also demonstrated that it is unsafe and not conservative to estimate hazard level based simply on a statistical approach, and numerical simulation results must be incorporated. This new approach opens up a new direction for future research. In the long run, flowdynamics-based GIS hazard mapping may better be received by city planners because of its sound theoretical background. Nevertheless, much work remains to be done, before a robust and efficient methodology can be applied for routine hazard assessment. 
Acknowledgements. The work described in this paper was fully supported by the Research Grants Council of the Hong Kong Special Administrative Region, China and the Hong Kong Polytechnic University (PolyU) through a research studentship to $\mathrm{KH}$ Lo and through Projects A-PE79 and A 226. The authors are indebted to T. Takahashi and H. Nakagawa of Japan by generously providing the computer program for our work and providing useful references of their works. The support from J. W. Z. Shi and Z. L. Li (of Department of Land Surveying and Geo- informatics of PolyU) on the use of GIS technology and from Y. L. Sze on the use of the software ArcGIS is appreciated.

Edited by: P. Reichenbach

Reviewed by: D. Calcaterra and W. Savage

\section{References}

Cancelli, A. and Crosta, G.: Hazard and risk assessment in rockfall prone areas, in: Risk and Reliability in Ground Engineering, edited by Skipp, B. O., Thomas Telford, 177-190, 1994.

Carrara, A., Cardinali, M., Detti, R., Guzzetti, F., Pasqui, V., and Reichenbach, P.: GIS techniques and statistical-models in evaluating landslide hazard, Earth Surface Processes and Landforms, 16 (5), 427-445, 1991.

Carrara, A., Guzzetti, F., Cardinali, M., and Reichenbach, P.: Use of GIS technology in the prediction and monitoring of landslide hazard, Natural Hazards, 20(2-3), 117-135, 1999.

Chau K. T., Sze, Y. L., Fung, M. K., Wong, W. Y., Fong, E. L., and Chan, L. C. P.: Landslide hazard analysis for Hong Kong using landslide inventory and GIS, Computers and Geosciences, in press, 2004.

Coppock, J. T.: GIS and natural hazards: An overview from a GIS perspective, in: Geographical Information Systems in Assessing Natural Hazards, edited by Carrara, A. and Guzzetti, F., Kluwer, Dordrecht, 21-34, 1995.

Dikau, R., Cavallin, A., and Jager, S.: Databases and GIS for landslide research in Europe, Geomorphology, 15(3-4), 227-239, 1996.

Dai, F. C. and Lee, C. F.: Landslide characteristics and, slope instability modeling using GIS, Lantau Island, Hong Kong, Geomorphology, 42(3-4), 213-228, 2002a.

Dai, F. C. and Lee, C. F.: Landslides on natural terrain - Physical characteristics and susceptibility mapping in Hong Kong, Mountain Research and Development, 22(1), 40-47, 2002 b.

Denlinger, R. P. and Iverson, R. M.: Flow of variably fluidized granular masses across three-dimensional terrain, 2. Numerical predictions and experimental tests, J. Geophys. Res., 106(B1), 553-566, 2001.

Einstein, H. H.: Landslide risk assessment procedure, in: Landslides, 5th Int. Sym. on Landslides, Vol. 2, Balkema, Rotterdam, 1075-1090, 1988.

Einstein, H. H.: Landslide risk-Systematic approaches to assessment, in: Landslide Risk Assessment, edited by Cruden, D. M. and Fell, R., Balkema, Rotterdam, 25-50, 1997.

Evans, N. C., Huang, S. W., and King, J. P.: The natural terrain landslide study phases I and II, GEO Report No. 73, GEO, CED, Hong Kong SAR Government, 128, 1999.

Fell, R. and Hartford, D.: Landslide risk management, in: Landslide Risk Assessment, edited by Cruden, D. M. and Fell, R., Balkema, Rotterdam, 51-109, 1997.
Ghilardi, P., Natale, L. and Savi, F.: Modeling Debris Flow Propagation and Deposition, Physics and Chemistry of the Earth, 26(9), 651-656, 2001.

Guzzetti, F., Cardinali, M., Reichenbach, P., and Carrara, A.: Comparing landslide maps: A case study in the Upper Tiber River basin, central Italy, Environmental Management, 25(3), 247263, 2000.

Guzzetti, F., Carrara, A., Cardinali, M., and Reichenbach, P.: Landslide hazard evulation: a review of current techniques and their application in a multi-scale study, Central Italy, Geomorphology, 31(1-4), 181-216, 1999.

Halcrow China Limited: Investigation of some selected landslides in 2000, GEO Report No. 129, GEO, Civil Engineering Department, HKSAR, 2002.

Hansen, A.: Landslide hazard analysis, in: Slope Instability, Chapter 13, edited by Brunsden, D. and Prior, D. B., Wiley, New York, 523-602, 1984.

Hungr, O.: Some methods of landslides hazard intensity mapping, in: Landslide Risk Assessment, edited by Cruden, D. M. and Fell, R., Balkema, Rotterdam, 215-226, 1997.

King, J. P.: The Tsing Shan debris flow, Special Project Report SPR 6/96, Hong Kong: Geotechnical Engineering Office, Civil Engineering Department, 1996.

Leroi, E.: Landslide risk mapping: Problems, limitation and developments, in: Landslide Risk Assessment, edited by Cruden, D. M. and Fell, R., Balkema, Rotterdam, 239-250, 1997.

Lo, K. H.: Numerical simulations of debris flow and their application to hazard mapping using GIS, MPhil. Dissertation, Department of Civil and Structural Engineering, The Hong Kong Polytechnic University, Hong Kong, 2003.

Lo, K. H. and Chau, K. T.: Debris Flow Simulations for Tsing Shan in Hong Kong, Third International Conference on DebrisFlow Hazards Mitigation: Mechanics, Prediction and Assessment, September 10-12, 2003, Davos, Switzerland, vol. 1, 577588, 2003.

Luzi, L., Pergalani, F., and Terlien, M. T. J.: Slope vulnerability to earthquakes at subregional scale, using probabilistic techniques and geographic information systems, Engineering Geology, 58(3-4), 313-336, 2000.

Miller, D. J. and Sias, J.: Deciphering large landslides: linking hydrological, groundwater and slope stability models through GIS, Hydrological Processes, 12(6), 923-941, 1998.

O'Brien, J. P., Julien, P. J., and Fullerton, W. T.: Two-dimensional water flood and mudflow simulation, J. Hydr. Res., 119(2), 244261, 1993.

Pierson, T.C.: Flow characteristics of large eruption-triggered debris flows at snow-clad volcanoes: Constraints for debris-flow models, J. Volcanol., 66, 283-294, 1995.

Savage, S. B. and Hutter, K.: The dynamics of avalanches of granular materials from initiation to runout, part I, Analysis, Acta Mechanica, 86, 201-223, 1991.

Takahashi, T.: Debris flow, Annual Reviews Fluid Mechanics, 13, 57-77, 1981.

Takahashi, T.: Debris flow, International Association for Hydraulic Research, Balkema, Rotterdam, 1991.

Takahashi, T., Nakagawa, H., Harada, T., and Yamashiki, Y.: Routing debris flows with particle segregation, J. Hydr. Res., 118(11), 1490-1507, 1992.

Varnes, D. J.: Landslide hazard zonation: A review of principles and practice, UNESCO, France, 1-63, 1984. 